\title{
Coexistence of cluster headache and paroxysmal hemicrania: does it exist? A case report and literature review
}

\author{
Nilima D. Shah $\cdot$ Sanjay Prakash
}

Received: 9 December 2008/Accepted: 29 January 2009/Published online: 11 March 2009

(C) Springer-Verlag 2009

\begin{abstract}
The coexistence of different types of trigeminal autonomic cephalalgias is a rare phenomenon. The two different types of headache may occur either at two different periods or simultaneously at the same time. We report a 22-year-old male who had cluster headache $(\mathrm{CH})$ and chronic paroxysmal hemicrania (CPH) since the onset of symptoms. Both types of headache responded to indomethacin. Review of the literature suggests that simultaneous occurrence of $\mathrm{CH}$ and $\mathrm{CPH}$ in a patient may be both over and under reported.
\end{abstract}

Keywords Cluster headache - Paroxysmal hemicrania · Trigeminal autonomic cephalalgias

\section{Introduction}

The coexistence of different primary headache disorders is not rare. However, there are only a few case reports of the coexistence of two different varieties of trigeminal autonomic cephalalgias (TACs) in the same patient. The two different types of headache may occur either at two different time periods or simultaneously at the same time

N. D. Shah

Department of Psychiatry, Medical College,

Baroda 390001, Gujarat, India

N. D. Shah · S. Prakash

Department of Neurology, Medical College, SSG Hospital,

Baroda 390001, Gujarat, India

S. Prakash $(\bowtie)$

O-19, Doctor's Quarter, Jail Road, Baroda 390001,

Gujarat, India

e-mail: drprakashs@yahoo.co.in
[1-5]. Here we report a patient with ipsilateral attacks of cluster headache $(\mathrm{CH})$ and chronic paroxysmal hemicrania $(\mathrm{CPH})$ at the same time. We also review the literature on coexisting $\mathrm{CH}$ and paroxysmal hemicrania $(\mathrm{PH})$.

\section{Case}

A 22-year old male presented with a 13-month history of recurrent daily headache. The pain, strictly on the left side, was centered on the left orbit radiating to frontal and infra orbital areas. The patient described the headache as very severe, sharp, and tearing type. The patient noticed two types of headache, one with a shorter and another with a longer duration. The usual duration of headache was 5-20 min for shorter duration type, and 2-3 h for longer duration type. However, overall the duration of attacks was variable, few minutes to few hours (up to $5 \mathrm{~h}$ ). The quality and severity of the pain was similar in almost all the episodes. Most of the attacks were associated with ipsilateral lacrimation, conjunctival injection, ptosis and rhinorrhea. There were occasional nausea, photophobia, and phonophobia. The patient denied the presence of any type of symptoms (including mild background headache) between two episodes of headache. During most of the attacks the patient cried or paced. There were occasional nocturnal attacks. No precipitating or aggravating factors were noted. The frequency of attacks was highly variable. He had a history of 10-25 short-lasting attacks in a day. He used to have four to ten attacks of longer duration in a week. The pain used to start abruptly. He could not predict (in early part of the attack) which attacks were going to last longer.

The patient received a lot of drugs before reporting to us. He took paracetamol, naproxen, oral sumatriptan and rizatriptan (as abortive treatment) on many occasions 
during the attack. There was history of improvement at several times within few minutes to $60 \mathrm{~min}$ after the administration of triptans. However, the patient was not sure about the efficacy of triptans as he had history of frequent attacks of shorter duration. Oxygen inhalation during an attack had never been tried. Prior prophylactic treatment with amitriptyline, flunarizine, paracetamol, naproxen, sodium valproate, and propranolol produced minimal or no effect.

The patient had no prior history of headache. Family history for headache was negative. He was nonalcoholic and a non-smoker. General and neurological examinations between two attacks were normal. Routine haematological and biochemical screening was normal. Magnetic resonance imaging of brain, orbit, pituitary and cervical spine revealed no abnormality. Magnetic resonance angiography was reported as normal.

We started indomethacin at a dose of $25 \mathrm{mg}$ tds. With this dose, he felt marked improvement in the frequency of the 'shorter duration' type of headache. In the next 10 days, the frequency of attacks was about less than one attack in a day. However, the frequency and intensity of the 'longer duration' type of headache remained unchanged. The dosage of indomethacin was gradually increased. At the dose of $50 \mathrm{mg}$ tds, the shorter duration attacks subsided completely and frequency of longer duration attacks decreased to two in the next week. The dosage of indomethacin was further increased. The longer duration attacks subsided completely at the dosage of $100 \mathrm{mg}$ tds (with famotidine for gastric protection). In the next 5 months of follow up (with indomethacin), he did not have any attack of headache.

\section{Discussion}

The TACs, a group of primary headache disorder, include $\mathrm{CH}, \mathrm{PH}$, and short-lasting unilateral neuralgiform headache attacks with conjunctival injection and tearing (SUNCT). These differ in attack duration, frequency, and the response to therapy. The duration of an attack of different TACs according to the International Headache Society (IHS) criteria are 5-240 s (SUNCT), 2-30 $\mathrm{min}$ (PH), 15-180 min $(\mathrm{CH})$. The frequency of different TACs are: SUNCT (3-200 per day), $\mathrm{PH}$ (>5 attacks per day for more than half the time), and $\mathrm{CH}$ (1 per alternate day to 8 per day). Response to indomethacin is an essential criterion for the diagnosis of PH [6].

Our patient distinctly recognized two types of headache, short-lasting (5-20 min) and long-lasting attacks (2-5 h). Many authors have suggested a trial of indomethacin at the start of treatment to detect the indomethacin-sensitive group in all patients diagnosed with TACs. Both the types of attacks showed response to indomethacin. We noted dose-response relation with indomethacin. The short attacks were eliminated at the dose of $50 \mathrm{mg}$ tds. However, $100 \mathrm{mg}$ tds dose was required for cessation of the longer attacks. As the patient showed marked response with indomethacin within a few days, we did not give the trial oxygen inhalation.

The whole spectrum of frequency and duration of the disease was not fitting in any one primary headache disorder. The foot note of IHS diagnostic criteria quote 'During part (but less than half) of the time-course of $\mathrm{CH}$, attacks may be less severe and/or of shorter or longer duration'. However, the frequency of 10-25 attacks in a day (almost daily) was against the diagnosis of $\mathrm{CH}$. In the same way, duration of an attack up to $5 \mathrm{~h}$ was against the diagnosis of PH. The absence of background headache ruled out the possibility of hemicrania continua (HC).

The shorter attacks completely fulfilled the IHS criteria for PH. The mean length of an attack of CPH is 17-21 min. The maximum reported duration of an attack is usually 3-4 h [7, 8]. However, Boes et al. [7] in a retrospective study on 74 patients of $\mathrm{CPH}$ found one patient with few attacks of $6 \mathrm{~h}$ duration. Cittadini et al. [8] in a prospective study on 31 patients of $\mathrm{PH}$ reported a patient who had an attack of $48 \mathrm{~h}$. Hence, one possible diagnosis in our case could be $\mathrm{CPH}$, similar to the cases reported by Boes et al. and Cittadini et al. However, our case was different in that long-lasting attacks (up to $5 \mathrm{~h}$ ) were more frequent. Hence, another possible diagnosis in our case would be simultaneous occurrence of probable chronic cluster headache $(\mathrm{CCH})$ and probable $\mathrm{CPH}$.

To date, we found only five cases in the literature where authors claimed the presence of $\mathrm{CH}$ and $\mathrm{PH}$ in the same patient (simultaneously or at two different periods of life) (Table 1). The first case report of $\mathrm{CPH}$ and $\mathrm{CH}$ in a same patient was described by Jotkowitz [1] in a 41-year-oldmale in whom the pattern of headache (frequency and duration) changed after 4 years. Initially, he had 1-3 headaches per day, each lasting 45-60 min. Indomethacin was not tried during these periods. Later on, after 4 years, frequency increased up to 8 per day and duration shortened to 20-30 min. The patient showed marked response in the frequency and severity of the headaches with indomethacin (150 mg/day). The author concluded that initial attack was typical of episodic $\mathrm{CH}$ and later on, it changed to $\mathrm{CPH}$.

Pearce et al. [2] reported a female patient who had history of migraine (16-20 years of age), episodic cluster headache (ECH) (48-47 years), and PH (a single bout at 58 years) at different periods in life. The patient's single episode of $\mathrm{PH}$ showed response to indomethacin after 22 days of therapy. There was no recurrence of $\mathrm{PH}$ like headache in about 7 months' follow up even after withdrawal of the drug. 
Table 1 Literature review of co-occurrence of cluster headache $(\mathrm{CH})$ and paroxysmal hemicrania $(\mathrm{PH})$

\begin{tabular}{|c|c|c|c|c|c|c|}
\hline Author & Age/sex & $\begin{array}{l}\text { Features } \\
\text { of } \mathrm{CH}\end{array}$ & $\begin{array}{l}\text { Features } \\
\text { of PH }\end{array}$ & $\begin{array}{l}\text { Interrelation between } \\
\mathrm{CH} \text { and } \mathrm{PH}\end{array}$ & Treatments & Comments on diagnosis \\
\hline Jotkowitz [1] & $43 \mathrm{Y} / \mathrm{M}$ & $\begin{array}{l}\mathrm{f}: 1-3 / \text { day } \\
\mathrm{d}: 45-60 \mathrm{mts}\end{array}$ & $\begin{array}{l}\text { f: } 8 / \text { day } \\
\text { d: } 20-30 \mathrm{mts}\end{array}$ & $\begin{array}{l}\mathrm{CH} \text { changed to } \mathrm{PH} \text { after } \\
4 \text { years }\end{array}$ & $\begin{array}{l}\text { Methysergide and } \\
\text { ergot for } \mathrm{CH} \\
\text { Indo For } \mathrm{PH}\end{array}$ & $\begin{array}{l}\text { Changed character } \\
\text { of headache } \\
\text { (PH) satisfy the IHS criteria } \\
\text { of } \mathrm{CH}\end{array}$ \\
\hline $\begin{array}{l}\text { Pearce et al. } \\
{[2]}\end{array}$ & $58 \mathrm{Y} / \mathrm{M}$ & $\begin{array}{l}\text { f: daily } \\
\text { d: } 30-120 \mathrm{mts}\end{array}$ & $\begin{array}{l}\mathrm{f}: 10-14 / \mathrm{day} \\
\mathrm{d}: 5-40 \mathrm{mts}\end{array}$ & $\begin{array}{l}\mathrm{CH} \text { changed to } \mathrm{PH} \text { after } \\
\text { about } 9-10 \text { years }\end{array}$ & $\begin{array}{l}\text { Ergot for } \mathrm{CH} \\
\text { Partial relief by } \\
\text { ergot in PH } \\
\text { Com. relief by Indo. } \\
\text { in PH }\end{array}$ & $\begin{array}{l}\text { Only } 1 \text { episode of } \mathrm{PH} \text { (no } \\
\text { recurrence after } \\
\text { withdrawal of indo) } \\
\text { Response by indo. in } \\
22 \text { days }\end{array}$ \\
\hline \multicolumn{7}{|c|}{ Tehindrazanarivelo et al. [3] } \\
\hline Case 1 & $33 \mathrm{Y} / \mathrm{M}$ & $\begin{array}{l}\text { f: } 2 / \text { day } \\
\text { d: } 120 \mathrm{mts}\end{array}$ & $\begin{array}{l}\text { f: } 20-30 / \text { day } \\
\text { d: } 10-20 \mathrm{mts}\end{array}$ & $\begin{array}{l}\text { Past history of } \mathrm{CH} \\
\text { Recent attacks include } \\
\text { both } \mathrm{PH} \text { and } \mathrm{CH}\end{array}$ & $\begin{array}{l}\text { Verapamil for } \mathrm{CH} \\
\text { Indo. for } \mathrm{PH}\end{array}$ & $\begin{array}{l}\text { Only } 1 \text { episode of } \mathrm{PH} \text { (no } \\
\text { recurrence after } \\
\text { withdrawal of indo) }^{\mathrm{a}}\end{array}$ \\
\hline Case 2 & $45 \mathrm{Y} / \mathrm{M}$ & $\begin{array}{l}\mathrm{f}: 2-3 / \text { day } \\
\mathrm{d}: 120 \mathrm{mts}\end{array}$ & $\begin{array}{l}\mathrm{f}: 15-30 / \text { day } \\
\mathrm{d}: 2-30 \mathrm{mts}\end{array}$ & $\begin{array}{l}\text { Past history of } \mathrm{CH} \\
\text { Recent attacks include } \\
\text { both } \mathrm{PH} \text { and } \mathrm{CH}\end{array}$ & $\begin{array}{l}\text { Verapamil for } \mathrm{CH} \\
\text { Indo. for } \mathrm{PH}\end{array}$ & $\begin{array}{l}\text { Only } 1 \text { episode of } \mathrm{PH} \text { (no } \\
\text { recurrence after } \\
\text { withdrawal of indo) }^{\mathrm{a}}\end{array}$ \\
\hline Centonze et al. [4] & $42 \mathrm{Y} / \mathrm{M}$ & $\begin{array}{l}\mathrm{f}: 2-3 / \text { day } \\
\mathrm{d}: 30-120 \mathrm{mts}\end{array}$ & $\begin{array}{l}\mathrm{f}: 8-16 / \text { day } \\
\mathrm{d}: 5-12 \mathrm{mts}\end{array}$ & $\begin{array}{l}\text { Past history of } \mathrm{CH} \\
\text { Recent attacks include } \\
\text { both } \mathrm{PH} \text { and } \mathrm{CH}\end{array}$ & $\begin{array}{l}\text { Verapamil for } \mathrm{CH} \\
\text { Indo. for } \mathrm{PH}\end{array}$ & $\begin{array}{l}\text { Only } 1 \text { episode of } \mathrm{PH} \text { (no } \\
\text { recurrence after } \\
\text { withdrawal of indo) }^{\mathrm{a}}\end{array}$ \\
\hline Gobel et al. ${ }^{\mathrm{b}}$ [5] & $47 / \mathrm{M}$ & b & $\mathrm{b}$ & $\mathrm{b}$ & b & $\mathrm{b}$ \\
\hline
\end{tabular}

a At least two attacks separated by pain-free remission periods of $\geq 1$ month are required for IHS criteria of EPH

b Details not available

com complete, $d$ duration, $f$ frequency, Indo Indomethacin, $m t s$ minutes, $Y$ years

Tehindrazanarivelo et al. [3] described two cases of ipsilateral $\mathrm{CH}$ and $\mathrm{CPH}$. Both patients, who had been suffering from $\mathrm{CH}$ for many years ( $>5$ years), developed simultaneous attacks of $\mathrm{PH}$ with the attacks of $\mathrm{CH}$. Both patients received indomethacin and verapamil at the same time, and it was concluded that indomethacin was effective for short-lasting attacks and verapamil for long-lasting attacks. However, an attempt to control both the types of attacks with a single drug (either verapamil or indomethacin) with maximal possible dose was not done. In the first case, short-lasting attacks of $\mathrm{PH}$ responded to indomethacin $(150 \mathrm{mg} / \mathrm{day})$. Verapamil was added for longer attacks and patient responded to $360 \mathrm{mg}$ daily. Indomethacin was tapered off after 6 weeks. There was no recurrence in the next 14 months. In the second patient, verapamil was started as initial drug and long-lasting attacks of $\mathrm{CH}$ subsided at the dose of $240 \mathrm{mg}$ daily. Indomethacin (200 mg daily) was added for short-lasting attacks. There was no recurrence of attacks even after tapering off and stopping of indomethacin in about next 12 months.

Another case of simultaneous occurrence of $\mathrm{CH}$ and $\mathrm{PH}$ was described by Centonze [4] in a 42-year-old male. The patient with the history of ECH for about 6 years developed PH-like attacks (short duration and higher frequency) in a fresh episode of $\mathrm{CH}$. The patient was already on verapamil (360 mg daily) for ECH. Indomethacin was added, and patient noted complete improvement on shorter attacks and partial improvement of longer attacks at the dose of $225 \mathrm{mg}$ daily. After 3 weeks, indomethacin was successfully discontinued. In about 9 months of follow up, there was no recurrence of shorter attacks.

Gobel et al. [5] reported successive occurrence of trigeminal neuralgia, SUNCT-syndrome, $\mathrm{CPH}$ and $\mathrm{CH}$ in one active headache period in a 47-year-old male. However, it is difficult to derive any conclusion from this case report (published in abstract form) as the details of $\mathrm{CPH}$ and $\mathrm{CH}$ are lacking.

The episodic form of $\mathrm{PH}$ is less frequent than chronic form of $\mathrm{PH}$ (in contrast to $\mathrm{CH}$ ). There are just a few case reports of episodic form of $\mathrm{PH}$ in the literature [9]. Hence, co-occurrence of $\mathrm{CH}$ with $\mathrm{CPH}$ would be perhaps possible rather than the co-occurrence of $\mathrm{CH}$ with $\mathrm{EPH}$, which is itself very rare. However, all the above-reported cases of $\mathrm{PH}$ (with $\mathrm{CH}$ ) are episodic in nature. At least two episodes, separated by at least 1 month of pain remission, are required to satisfy the IHS diagnostic criteria for episodic paroxysmal hemicrania (EPH) [6]. However, no patient had two or more episodes of PH-like attacks (frequency and duration) in the history. Moreover, no patient had a trial of an increased dose of previously effective drugs. 
In Pearce et al. case report the response to indomethacin was not immediate. Response occurred 22 days after administration of indomethacin therapy. All reported case series of EPH showed response within $24 \mathrm{~h}$ after the administration of indomethacin. This further created the doubt about the diagnosis of PH in this patient.

There is considerable overlap in the diagnostic criteria of $\mathrm{CH}$ and $\mathrm{PH}$ in the IHS classification. The headache duration of 15-30 min and headache frequency of 5-8 in a day is common for both $\mathrm{CH}$ and $\mathrm{PH}$ [6]. Even after the change of duration and frequency of headache, Jotkowitz's case satisfies the IHS criteria for $\mathrm{CH}$.

The overlap between $\mathrm{CH}$ and $\mathrm{PH}$ becomes more evident when one reviews the clinical profiles of both these primary headache disorders. In the patients of $\mathrm{CH}$, the duration of an attack may be as low as 2 min and the frequency may be as high as 30 in a day $[10,11]$. The frequency of $\mathrm{ECH}$ might increase and of $\mathrm{CCH}$ may decrease over the years [12]. There is considerable overlap between $\mathrm{CH}$ and $\mathrm{PH}$ even in treatment modalities.

Therefore, the aforementioned cases may not be true representations of $\mathrm{CH}$ and $\mathrm{PH}$ in the same patient. The possibility of fluctuation (frequency and duration) of $\mathrm{CH}$ attacks itself (or? atypical form) cannot be ruled out.

Leon et al. [13] reported a 55-year-old woman with recurrent bouts (of 2 months) of headache since her adolescence. In adolescent and adulthood periods, individual attacks were of $20 \mathrm{~min}$. The frequency of attacks was 4-6 times in a day. The attacks were controlled with $150 \mathrm{mg}$ of indomethacin. There was a change in headache periodicity and frequency during 47-55 years of age. There was no remission period during these 8 years and headache frequency increased to 15 attacks in a day. The patient needed 400-500 mg of indomethacin to control this changed pattern of headache. After 8 years of continuous headache attacks, the pattern of headache reverted to the previous pattern (requiring $150 \mathrm{mg}$ indomethacin daily). The authors reported these two types of attacks as EPH and $\mathrm{CPH}$. However, Lipton et al. (after reviewing this case) suggested that her early attack was ECH that evolved into $\mathrm{CPH}$ [14]. This case fulfilled the IHS criteria of both HC and $\mathrm{CPH}$ (in two different period of life), and it may be the true representation of $\mathrm{CH}$ and $\mathrm{PH}$ in the same patient.

Blau et al. [15] reported recurrent bouts (11-13 weeks) of headache since the age of 16 in a 40-year-old female. In each bout, during the first and third months she had two to three attacks in a day. In the second month, the frequency of headache used to increase up to one in an hour. Individual attacks persisted for 10-20 min. The patient showed complete response to indomethacin (150 mg daily) and prednisolone separately on two different occasions. The author's diagnosis was EPH. However, she was diagnosed as a case of $\mathrm{CH}$ in the past. This case poses a diagnostic problem, as the frequency of headache attacks does not fit into any IHS classification of primary headache disorders. The headache attacks in the first and third months fulfilled the criteria of $\mathrm{CH}$. However, in the second month of a bout it was EPH. Therefore, this patient might have diagnosis of either EPH with fluctuating frequency, $\mathrm{CH}$ with fluctuating frequency or a combination of both EPH and ECH.

Our case was probably an example of co existence of $\mathrm{CPH}$ and $\mathrm{CCH}$. It is probably the first case where features of both $\mathrm{CH}$ and $\mathrm{PH}$ were present since the onset. However, we cannot rule out the possibility of either $\mathrm{PH}$ or $\mathrm{CH}$ alone (with marked variation in the frequency and duration of attacks). The presence of nausea, photophobia, phonophobia, response of oral triptans on few attacks may suggest overlap of migraine in the patient. However, these features are not uncommon even in pure form of $\mathrm{PH}$ and $\mathrm{CH}[7,8$, 10]. Another unique point in this patient was response to both the types of headache attacks by a single-drug therapy (indomethacin). Response to two different types of headache by a single agent has been reported in only one patient in the literature. Rozen [16] reported a patient with simultaneous occurrence of both $\mathrm{HC}$ and $\mathrm{CH}$ in the same individual. Both types of headache syndromes responded to verapamil.

Response to indomethacin is an essential criterion for the diagnosis of $\mathrm{PH}$. Indomethacin is considered as a drug ineffective for the patients of $\mathrm{CH}$. Although response to indomethacin is not against the IHS criteria for $\mathrm{CH}$, physicians hesitate in making the diagnosis of $\mathrm{CH}$ if a patient shows response to indomethacin, even in those people who clearly fulfil the IHS criteria for $\mathrm{CH}$. There are many reports in the literature where cases of $\mathrm{CH}$ were wrongly diagnosed as $\mathrm{PH}$ because of the presence of positive response to indomethacin [9, 13, 17]. Indomethacin has never been evaluated systematically for $\mathrm{CH}$ prophylaxis. There are many case reports in the literature where indomethacin was effective in the patients of $\mathrm{CH}[18,19]$.

Trigeminal autonomic reflex (TAR) (consists of a brainstem connection between trigeminal nerve and facial parasympathetic outflow) is considered essential for the manifestations of the trigeminal autonomic pain syndromes. Activation of trigeminal autonomic reflex is responsible for the acute attacks of TACs. The triggering factor for the activation of this reflex is probably situated in the hypothalamus or a closely related structure [20]. However, the duration and frequency of headache attacks depend on what side (or type of neuron) of the hypothalamus is activated [20]. In $\mathrm{CH}$ hypothalamic activation occurs ipsilateral to the side of the headache while in $\mathrm{PH}$ hypothalamic activation occurs contralateral to the side of headache [20]. Activation of two different sites may be a possible explanation for variability in the duration of attacks in our patient. 
Our review of the literature suggests that co-occurrence of $\mathrm{CH}$ and $\mathrm{PH}$ may be both over and under diagnosed. This is because of the overlap in the frequency and pattern of both the diseases. Response to indomethacin is another critical point regarding this issue. One should be very careful in making the diagnosis $\mathrm{PH}$ just because of the presence of response to indomethacin. Our case further strengthens the view that marked overlaps exist between $\mathrm{CH}$ and $\mathrm{PH}$, and these two may not be two discrete entities (as suggested by many authors) [19]. Moreover, the responses to one single agent for two different headache syndromes in our patient and in Rozen's case report suggests that the dose of previously effective drug should be increased (rather than to add new drug) for the change in the pattern of headache and for co existence of two different types of headache syndrome at the same time.

\section{Conflict of interest None.}

\section{References}

1. Jotkowitz S (1978) Chronic paroxysmal hemicrania and cluster. Ann Neurol 4:389

2. Pearce SHS, Cox JGC, Pearce JMS (1987) Chronic paroxysmal hemicrania, episodic cluster headache and classic migrainein one patient. J Neurol Neurosurg Psychiatry 50:1699-1700

3. Tehindrazanarivelo AD, Visy JM, Bousser MG (1992) Ipsilateral cluster headache and chronic paroxysmal hemicrania: two case reports. Cephalalgia 12:318-320

4. Centonze V, Bassi A, Causarano V, Dalfino L, Centonze A, Albano O (2000) Simultaneous occurrence of ipsilateral cluster headache and chronic paroxysmal hemicrania: a case report. Headache 40:54-56

5. Göbel H, Heinze A, Heinze-Kuhn K (2000) Trigeminal neuralgia, SUNCT syndrome, chronic paroxysmal hemicrania, cluster headache and migraine in one patient: a case report. Cephalalgia 20:330-331
6. Headache Classification Subcommittee of the International Headache Society (2004) The International Classification of Headache Disorders, 2nd edn. Cephalalgia 24(Suppl 1):1-160

7. Boes CJ, Dodick DW (2002) Refining the clinical spectrum of chronic paroxysmal hemicrania: a review of 74 patients. Headache 42:699-708

8. Cittadini E, Matharu MS, Peter J, Goadsby PJ (2008) Paroxysmal hemicrania: a prospective clinical study of 31 cases. Brain 131:1142-1155

9. Veloso GG, Kaup AO, Peres MFP, Zukerman E (2001) Episodic paroxysmal hemicrania with seasonal variation. Case report and the EPH-cluster headache continuum hypothesis. Arq Neuropsiquiatr 59(4):944-947

10. Schurks M, Kurth T, de Jesus J, Jonjic M, Rosskopf D, Diener HC (2006) Cluster headache: clinical presentation, lifestyle features, and medical treatment. Headache 46:1246-1254

11. Bogucki A, Niewodniczy A (1984) Case report: chronic cluster headache with unusual high frequency of attacks. Differential diagnosis with CPH. Headache 24:150-151

12. Manzoni GC, Micieli G, Granella F, Tassorelli C, Zanferrari C, Cavallini A (1991) Cluster headache course over ten years in 189 patients. Cephalalgia 11:169-174

13. Leon JC, Monton FI (1994) Paroxysmal hemicrania. Neurology 44:2215-2216

14. Lipton RB, Newman LC, Solomon S (1994) Paroxysmal hemicrania. Neurology 44:2215-2216

15. Blau JN, Engel H (1990) Episodic paroxysmal hemicrania: a further case and review of the literature. J Neurol Neurosurg Psychiatry 53:343-344

16. Rozen TD (2006) Verapamil-responsive hemicrania continua in apatient with episodic cluster headache. Cephalalgia 26:351-353

17. Fuad F, Jones NS (2002) Paroxysmal hemicrania and cluster headache: two discrete entities or is there an overlap? Clin Otolaryngol 27:472-479

18. Watson CPN, Evans RJ (1987) Chronic Cluster Headache: A Review of 60 Patients. Headache 27:158-165

19. Prakash S, Dholakia SY, Shah KA (2008) A patient with chronic cluster headache responsive to high-dose indomethacin: is there an overlap with chronic paroxysmal hemicrania? Cephalalgia 28:778-781

20. May A (2005) Cluster headache: pathogenesis, diagnosis, and management. Lancet 366:843-855 